\title{
Pattern of social media use among youth: implication for social media literacy
}

\author{
Happy Baglari ${ }^{1}$, Manoj Kumar Sharma ${ }^{2 *}$, P Marimuthu ${ }^{3}$ and Suma N $^{1}$ \\ ${ }^{1}$ Department of Clinical psychology, NIMHANS, Bengaluru, Karnataka, India \\ ${ }^{2}$ Clinical Psychology, SHUT clinic (Service for Healthy use of Technology), National Institute of Mental health \& Neurosciences, Bengaluru, Karnataka, India \\ ${ }^{3}$ Biostatistics, NIMHANS, Bengaluru, Karnataka, India
}

\begin{abstract}
Background: Social media use has increased tremendously over the years and its use has made the communication very easy with others. Social media used for sharing various perspective of life, which also includes sharing their experiences/ facts/ videos and other information.

Material \& methods: The study explored the Social Media use among 300 youth in the age group of 18-25 years. Background data sheets, Social Media Exploration Sheet were administered in the group setting.

Results: It revealed the age of initiation in the age group of 12 to 18 years (37.2\% Facebook users for 12 years; 54.0 WhatsApp users for 16 years and $38.3 \%$ Instagram users for 18 years. Maximum time spent was 120 minutes and minimum was 25 minutes for Facebook, Whatsapp and Instagram. The use of social media was more among the females. $40 \%$ also reported that they displayed their identity on social media. Life style disturbance in academics and daily life activities was seen secondary to social media use (99.7\%).62.3\% reported social media helped in communication with others and $75 \%$ shared information/videos/images/information through Social Media.
\end{abstract}

Conclusions: It can be used to evolve psycho educational model for bringing intervention for management of social media use.

\section{Introduction}

Recent years has seen a tremendous increase in exposure to social media such as Facebook, WhatsApp, Twitter among adolescents. The use of social media made the communication very easy with others, promoting user-generated content and interactions among users [1]. Social media used for sharing various perspective of life, which also includes sharing their experiences/ facts/ videos and other information. Social networking, which is one of the main indicators of the technology era, attracts people of all ages, while the virtual world goes beyond the real life via the applications it offers. Especially young adults show an intense interest in social media which is an extension of the Internet technology.

The Global social media research on "Digital in 2019" reported that there is a global increase in social media usage since January 2018 (9\%) and the number of social media users worldwide in 2019 is 3.484 billion. YouTube, Instagram and Snapchat are the most popular online platforms among teens, and the Indian teenagers are getting more and more attached to it [2]. According to a new Pew Research Center survey, $95 \%$ of teens have access to a smartphone, and $45 \%$ say they are online 'almost constantly'. Today, roughly half (51\%) of U.S. teens ages 13 to 17 use Facebook, notably lower than use of YouTube, Instagram or Snapchat.

The increased use of social networking influenced culture and interpersonal communication among youth. It helped bring friends and family closer for those living in distant locations, low additional cost of connectivity, sharing information, voicing opinions and updating each other on happenings in their lives. Studies also showed that the Social Media facilitate business promotion and interpersonal communication and also it provides platform for individuals to express themselves [3].
On contrary, the majority of the respondents agreed that social media usage interferes with their routine daily activity, academic performance, sleep pattern and mental health issues [4-8]. In relation to the above factors, one of the studies also showed that internet use scores have significant negative correlation between real life bonding capital and self-esteem and positive correlation with online bonding and conflicts in interpersonal relationships [9].

$26.7 \%$ of people with social media addiction have reported that they have sleep-related difficulties 2-3 times per week. Those participants with underlying Social Media addiction tend to rate level of severity of their last sleeping issue as high or extremely high as compared to participants who do not have an underlying addiction.

Facebook was commonly used among social media addicts (38.9\%) whereas, among social media non-addicts WhatsApp was commonly used (41.2\%). Further exploring difference between Government and private college students, they concluded that Internet Gaming (31\%), and Facebook (57.3\%) was commonly used by social media addicts in Government and Private colleges, respectively. The prevalence of social media addiction was $36.9 \%$ among users, distributed equally

*Correspondence to: Manoj Kumar Sharma, Professor of Clinical Psychology, SHUT clinic(Service for Healthy use of Technology), National Institute of Mental health \& Neurosciences, Bengaluru, Karnataka, India; E-mail: shutclinic@gmail.com

Key words: social media, well-being, distress, literacy

Received: March 17, 2020; Accepted: March 23, 2020; Published: March 31, 2020 
among private and Government PUs. The most common health problem identified was strain on eyes (38.4\%), anger (25.5\%), and sleep disturbance $(26.1 \%)$. Social media addiction was found in over onethirds of subjects and majority had mild addiction [10].

Mailing and surfing internet are two common reasons for using Internet from times of Web 2.0 (Web technologies in 90s). In Indian youth, social networking websites are growing to gain momentum in its popularity. Almost $30 \%$ of the respondents were members of Orkut and $50 \%$ in facebook. While other sites mentioned were Tagged, Netlog, MySpace, WAYN, Hi5, BigAdda, Linkedin, Stylefm, Twitter, Ning, Indyarocks, Friendster, and ebuddy [11].

Addiction was seen in $70.7 \%$ and was more common in the age group of 17 years and above. Among the 388 users, the most common sites visited were WhatsApp [used by 277 (82\%) of the sample], followed by Facebook used by 254 (75.1\%) and Instagram used by 114 users representing $33.7 \%$ of the study sample. Smartphones were the most common means of accessing the SNS, followed by desktop/ laptop computers at home. The SNS users opined that their online accounts carry real information about them. Social Networking affected their academic performance by interfering with the ability to study or complete assignments in the last one month; late in handing an assignment. In the current study, the association of addiction to SNS with the gender of the subject is not so significant with males (71.6\%) higher in number compared to females (69.7\%) [12].

The pattern of social networking usage and impact in order to determine the social networking addiction. The author also reviewed benefits of the social networking sites in culture development, building self-identity, developing relationships and acquisition of social, communication, and technical skills. Negative aspects identified were lack of privacy, users vulnerable to crime, constant browsing, social detriments like poor social skills, emotional trauma, addictive behavior, depression anxiety and loneliness, and misinformation [13].

$45.5 \%$ of the respondents have been using the social media sites for more than 1 year, $34.5 \%$ of the respondents have been using the social media sites for $6-12$ months and $20 \%$ of the respondents have been using the social media sites for less than 6 months. Study further highlighted that the respondents falling under 15-25 years are using social media more when compared to other age category. $52.5 \%$ of the respondents have opined that they are addicted towards social media sites and $47.5 \%$ of the respondents have opined that they are not addicted towards social media sites. 'Whats App' was ranked as the first social media site and 'Facebook' was ranked as second [14].

Heavy users of social networking sites, with $80 \%$ using at least one site or more (with Facebook being the most popular site) and more than $50 \%$ logging on to their site at least once a day. Males were significantly more likely than females to place self-promoting pictures or comments (involving sex or alcohol) on their profile, whereas females were significantly more likely than males to post romantic or "cute" pictures and/or information [15].

$48 \%$ of students $(\mathrm{N}=416)$ met the criteria for addiction and significant differences was observed for gender (in favor of male), education (bachelor course), monthly income (low income), social status (unmarried), hours of daily use (4hrs or more) in the degree of addiction [16].

23 subjects have been found to be internet addicts i.e. have scores 80-100. Among 23 (9.5\%) internet addicts found in the study $15(6.1 \%)$ were males and $8(3.3 \%)$ were females [17].
The significant differences was observed for gender, computer ownership (preferring desktop and laptop than mobile) and purpose of internet use (social networking and gaming rather than educational) as well as psychiatric symptoms such as depression between the two groups [18].

Addictive use was present among $1.3 \%$ ( $2 \%$ males \& $0.6 \%$ females) for internet; $4.1 \%$ (5\% males \& $3.1 \%$ females) for mobile phones; $3.5 \%$ for social networking sites. Statistically significant differences were observed in relation to family status for internet and face book addictions. It was more among singles, unmarried and lesser in joint families. The number of years of marriage has negative correlation with shopping, sex, mobile, internet and facebook addiction. Physical (eye strain)/Psychological distress (decrease sleep, irritability and restlessness) was present as a morbidity- $6.8 \%$ with mobile phone addiction; $4.2 \%$ with internet use and $3 \%$ with social networking sites, $3.3 \%$ wanted to change their internet activities and $4.2 \%$ wanted cut down expenses on mobile phone [19].

Review of literature shows that how in recent years the Social Media use has increased a lot among the young adults. There is a need to assess the pattern of use social media among youths and sensitize user for healthy use of technology. These finding will have implication for research, for promotion of awareness among users as well as use of social media as a modality to promote healthy behaviors.

\section{Material \& methods:}

\section{Aim: To explore the pattern of social media among youth}

Study design: 300 subjects in the age group of 18-25 years, having minimum one year use of social media, were selected using survey methodology from academic Institution based in Karnataka. Subjects having medical condition which interfere in taking assessments were excluded. The study got Institute Ethic approval.

\section{Tools}

Background data sheet: It was prepared by the researcher to collect information about which includes details such as date of birth, age, sex, religion, education, socio-economic status, marital status, language known etc.

Social media exploration sheet: The questions were evolved through focus group discussion of mental health professionals( 10 ; Having experience of 5 years or more in the area of mental health) and users( 10;using social media for the last one year) to assess the effect of social media on addictive behaviors through focused group discussion (of mental health expert working in the addiction, social media users in the age group of 18-25 years) to cover presentation of addictive behaviors on social media; online peer reaction/peer pressure; users expectancy; initiation, modality of initiation etc.

\section{Procedure}

The study was carried out after obtaining the informed consent of the participants, group administration of Background data sheet, Social Media Exploration Sheet was carried out. 300 completed protocols were included in the study

Statistical analysis: The data was analyzed using descriptive statistics such as mean, standard deviation, percentage and frequencies were used to analyze the demographic details. Chi- Square was used to assess the relationship among the variables and parametric statistic was used for continuous variable. The probability level of 0.05 and 0.01 were used. 


\section{Results}

The study consisted of 300 samples. It included 144 males and 156 females, unmarried attending graduation course belongs to Middle Socioeconomic status to Upper socio-economic status.

Table 1 showed the median age for initiating the use of social media i.e., 13 years for Facebook, 16years for WhatsApp and 17 years for Instagram

Table 2 showed Facebook use was highest among male (51.4\%). WhatsApp use was highest among female (56.7 \%) and Instagram use was highest among females (52.33\%)

Table 3 showed the Whatapps /Instgram were the most frequently used modality.

Table 4 showed lack of utility for Twitter and Other Social Media. The utility was high for Whatapps and Instagram.

Table 5 showed $62.3 \%$ reported social media helped in communication with others and $75 \%$ share information/videos/ images/information through Social Media.

Table 6 showed disturbance of lifestyle due to use of Social Media. $59.3 \%$ regrets after sharing their photos/videos/personal information. $80.7 \%$ reported delays or postponing daily activities due to Social Media Use.

\section{Discussion \& conclusion}

Social media is most popular among youth as it facilitates the sharing of ideas, information, and thoughts through the building of virtual networks and communities. It facilitates social interaction, through blogs, wikis, media (audio, photo, video, text) sharing tools, networking platforms (including Facebook) and virtual worlds [20]. The study aimed at exploring the relationship of social media use among youth. This study was conducted among 300 samples which included 144 males and 156 females.

Table 1. Social Media Initiation

\begin{tabular}{|c|c|c|c|c|}
\hline Social Media & Median & Age & Frequency & Percentage \\
\hline \multirow{3}{*}{ Facebook } & \multirow{3}{*}{13} & 12 & 81 & 37.2 \\
\hline & & 13 & 67 & 30.7 \\
\hline & & 14 & 70 & 32.1 \\
\hline \multirow{5}{*}{ Whatsapp } & \multirow{5}{*}{16} & 14 & 24 & 8.0 \\
\hline & & 15 & 80 & 26.7 \\
\hline & & 16 & 162 & 54.0 \\
\hline & & 17 & 30 & 10.0 \\
\hline & & 18 & 4 & 1.3 \\
\hline \multirow{4}{*}{ Instagram } & \multirow{4}{*}{17} & 15 & 13 & 4.3 \\
\hline & & 16 & 80 & 26.7 \\
\hline & & 17 & 92 & 30.7 \\
\hline & & 18 & 115 & 38.3 \\
\hline
\end{tabular}

Table 2. Pattern of Social Media use in relation to gender

\begin{tabular}{|c|c|c|c|}
\hline Variable & Gender & Frequency & Percentile \\
\hline \multirow{2}{*}{ Overall Media Use } & Male & 144 & 48.0 \\
\cline { 2 - 4 } & Female & 156 & 52.0 \\
\hline \multirow{2}{*}{ Facebook } & Male & 112 & 51.4 \\
\cline { 2 - 4 } & Female & 106 & 48.6 \\
\hline \multirow{2}{*}{ Whatsapp } & Male & 130 & 43.33 \\
\cline { 2 - 4 } & Female & 170 & 56.7 \\
\hline \multirow{2}{*}{ Instagram } & Male & 143 & 47.7 \\
\cline { 2 - 4 } & Female & 157 & 52.33 \\
\hline
\end{tabular}

Table 3. Time spent on social media per day

\begin{tabular}{|c|c|c|c|c|}
\hline Social Media & Median & Percentile & $\begin{array}{c}\text { Percent } \\
\text { (Minimum Use) }\end{array}$ & $\begin{array}{c}\text { Percent } \\
\text { (Maximum Use) }\end{array}$ \\
\hline \multirow{3}{*}{ Facebook } & \multirow{3}{*}{$\begin{array}{l}17.50 \text { (Minimum) } \\
45.00 \text { (Maximum) }\end{array}$} & 25 & 10.00 & 25.00 \\
\hline & & 50 & 17.50 & 45.00 \\
\hline & & 75 & 20.00 & 60.00 \\
\hline \multirow{3}{*}{ Whatsapp } & \multirow{3}{*}{$\begin{array}{l}20.00 \text { (Minimum) } \\
85.00 \text { (Maximum) }\end{array}$} & 25 & 15.00 & 60.00 \\
\hline & & 50 & 20.00 & 85.00 \\
\hline & & 75 & 30.00 & 120.00 \\
\hline \multirow{3}{*}{ Instagram } & \multirow{3}{*}{$\begin{array}{l}30.00 \text { (Minimum) } \\
90.00 \text { (Maximum) }\end{array}$} & 25 & 30.00 & 90.00 \\
\hline & & 50 & 30.00 & 80.00 \\
\hline & & 75 & 35.00 & 120.00 \\
\hline \multirow{3}{*}{$\begin{array}{l}\text { Others (media } \\
\text { sharing, social } \\
\text { news) }\end{array}$} & \multirow{3}{*}{$\begin{array}{l}\text { 10.00(Minimum) } \\
\text { 10.00(Maximum) }\end{array}$} & 25 & 0.00 & 0.00 \\
\hline & & 50 & 10.00 & 20.00 \\
\hline & & 75 & 15.00 & 30.00 \\
\hline
\end{tabular}

Table 4. Usefulness/ utility of Social Media in daily life.

\begin{tabular}{|c|c|c|c|}
\hline \multirow{2}{*}{ Social Media } & \multicolumn{2}{|c|}{ Frequency } & Percentage \\
\hline \multirow{2}{*}{ Facebook } & Yes & 217 & 72.3 \\
\cline { 2 - 4 } & No & 83 & 27.7 \\
\hline \multirow{2}{*}{ Whatsapp } & Yes & 300 & 100 \\
\cline { 2 - 4 } & No & 0 & 0 \\
\hline \multirow{2}{*}{ Instagram } & Yes & 300 & 100 \\
\hline \multirow{2}{*}{ Twitter } & No & 0 & 0 \\
\hline \multirow{2}{*}{ Others } & Yes & 0 & 0 \\
\hline & No & 300 & 100 \\
\hline & Yes & 123 & 41.0 \\
\hline
\end{tabular}

Table 5. Factors related to positive use of social media

\begin{tabular}{|l|c|c|c|}
\hline Factors & & Frequency & Percentage \\
\hline \multirow{2}{*}{ Interpersonal Communication } & Yes & 187 & 62.3 \\
\cline { 2 - 4 } & No & 113 & 37.7 \\
\hline \multirow{2}{*}{ Sharing Information/Post } & Yes & 255 & 75.0 \\
\cline { 2 - 4 } & No & 75 & 25.0 \\
\hline
\end{tabular}

Table 6. Negative impact of Social Media Use

\begin{tabular}{|l|c|c|c|}
\hline Factors & & Frequency & Percentage \\
\hline \multirow{2}{*}{ Daily routines disturbance } & Yes & 299 & 99.7 \\
\cline { 2 - 4 } & No & 1 & 0.3 \\
\hline \multirow{2}{*}{ Lleep Disturbances } & Yes & 219 & 73.0 \\
\hline \multirow{2}{*}{ Lack of Control } & No & 81 & 27.0 \\
\hline \multirow{2}{*}{ Offline Communication } & Nes & 240 & 80.0 \\
\hline \multirow{2}{*}{ Academic Performances } & Yes & 185 & 20.0 \\
\hline \multirow{2}{*}{ Privacy/Security (Sharing Personal } & No & 115 & 61.7 \\
\cline { 2 - 4 } Information) & Yes & 299 & 38.3 \\
\hline \multirow{2}{*}{ Postponing/Delaying Activities } & No & 1 & 99.7 \\
\cline { 2 - 4 } & Yes & 178 & 0.3 \\
\hline \multirow{2}{*}{ Fake Identity } & No & 58 & 40.7 \\
\hline
\end{tabular}

The study showed that $37.2 \%$ of individual initiate their use of Facebook at the age of 13 years, WhatsApp at the age of 16 years (54.0\%) and Instagram was at the age of 18 years (38.3\%) (Table 1). These results were compatible with the findings of Kirik, et al. who stated that social media use was high among young teenagers of age 14-17 years. Facebook, WhatsApp, YouTube, Instagram and Snapchat are the most popular online platforms among teen [21]. In relation to the gender, 
our study found that Facebook use was highest among male (51.4\%). WhatsApp use was highest among female (56.7\%) and Instagram use was highest among females (52.33\%) (Table 2). Research showed that compared with women, men on average spend more time on internet and involve in broader range of online activities. [22]

The data compiled by Statista 2018 showed that $57 \%$ of the platform's global account profiles are maintained by male, whereas $43 \%$ by female, which is in accordance with our findings. Facebook facilitates online communication and to develop relationship. Users can write private messages, chat, comments, and wall posts - messages that publicly appear on a user's personal page, mostly employed to connect with people and to know them better [23]. Men engages in Facebook to develop new relationship, online dating and group activities [24]. On the other hand, women more willingly use Internet to communication, social support and personal identity such as WhatsApp, Instagram and Social Network Sites [25]. Female use of Instagram largely influenced by body image concerns and social competence [26]. In accordance to our results, research conducted by Montag, et al. also found that Females use WhatsApp for significantly longer periods of time than males and younger age was associated with longer duration of WhatsApp use.

\section{Positive impact of social media use}

Web-based social networking gives the advantage for connecting people from all over the world. Respondents in the study, opinioned that Social media is an effective communication tool, which ena users to communicate with other social media users within a frac of time. $62.3 \%$ reported that social media helped in communica with others and $75 \%$ share information/videos/images through sc media (Table 5).

In relation to the utility of social media, study found that Adoles perceived Facebook (72.3 \%) and WhatsApp (82\%) more useful sharing photos, videos, text and other information (Table 4). Howe sample did not report of any usefulness in terms of Twitter and $\mathrm{O}$ Social Media. Due to online communication through social me adolescents' developed social connectedness and well- being [27].

\section{Negative impact of social media use}

Despite the popularity of social media among youth for persi communication, entertainment, and social growth. The nega effect of increased social media use [28-30]. Excessive Internet was associated with impaired functioning at work, poor acade performance at schools and colleges, sleep deprivation, $F$ functioning of the immune system and lack of proper exercise [31, In addition, social media use and adolescent mental health reve: that increased social media use was related to online harassment, $\mathrm{F} \sim$... sleep, low self-esteem and poor body image. Females are more prone to develop higher depressive symptom in association with social media use [33].

Our current study also revealed that $99.7 \%$ experienced disturbances in their daily routines, poor academic performances and sleep disturbance (73\%) (Table 6). Adolescents are more prone to involve in Social media for their identity and social interaction, which in contrast limiting the communication between friends, family members and other significant others. Young adults spend less time with their family members and friends in a number of activities (watching TV, eating meals, chatting, shopping and spending time outside) leading to perceived lower social support and Internet Addiction [34]. In addition, study also found that $80.7 \%$ involve in postponing / Procrastination activities due to loss of control over social media use, leading to academic difficulty $[35,36]$. About $73 \%$ reported to have experienced sleep related issues, which is in accordance with the previous research findings that, which stated that heavy internet use is associated with Insomnia and other sleeping disturbances. Interestingly, study highlighted that $60 \%$ of social media users faked their identity and $59.3 \%$ regretted sharing personal photos, videos on social media and also reported that lots of Facebook users share partially fraud data in their user profiles $[37,38]$.

The present study is one of the first studies to look into the pattern of Social Media use among youth. The limitations observed in the study that it did not use Interview based qualitative methodology with people. The study also implicated the need to evolve well-being program among Youth to promote healthy lifestyle. The findings can also be used to sensitize Mental Health professionals even at the college level for screening and then evolving psycho educational model for bringing life style changes, emotion coping, family support.

\section{Acknowledgement}

National Institute of Mental Health \& Neurosciences, Bengaluru, Karnataka for permitting to carry out the Non funded M. Phil work.

\section{Compliance with ethical standard}

There was no conflict of interest in relation to present work as well as informed consent of the human subjects had been taken prior to inclusion in the study.

\section{Disclosure of potential conflict of interest}

Not applicable.

\section{Conflict of interest}

Authors of the paper did not have any conflict of interest.

\section{Statement of human right}

The studies have been approved by the Institutional and/or national research ethics committee.

\section{Research involving human participants and/or animals}

All procedures performed in studies involving human participants were in accordance with the ethical standards of the institutional and/ or national research committee and with the 1964 Helsinki declaration and its later amendments or comparable ethical standards.

\section{References}

1. Madden M, Lenhart A, Duggan M, Cortesi S, Gasser U (2005) Teens and technology. Pew Internet \& American Life Project.

2. Anderson M, Jiang J Teens (2018) social media \& technology. Pew Research Center.

3. Aral S, Dellarocas C, Godes D (2013) Introduction to the special issue-social media and business transformation: a framework for research. Information Systems Research 24: $3-13$

4. O'Keeffe GS, Clarke-Pearson K (2011) The impact of social media on children, adolescents, and families. Pediatrics 127: 800-880.

5. Al-Rahmi WM, Othman MS (2013) The impact of social media use on academic performance among university students: A pilot study. Journal of Information Systems Research and Innovation.

6. Levenson JC, Shensa A, Sidani JE, Colditz JB, Primack BA (2016) The association between social media use and sleep disturbance among young adults. Prev Med 85: 36-41. [Crossref]

7. Tavernier R, Willoughby T (2014) Sleep problems: predictor or outcome of media use among emerging adults at university? J Sleep Res 23: 389-396. [Crossref] 
8. Caplan S, Buyske S (2015) Depression, Help seeking ad Self-Recognition of Depression among Dominican, Ecuadorian and Colombian Immigrant Primary Care Patients in the Northeastern United States. Int J Environ Res Public Health 12: 1045010474. [Crossref]

9. Sharma MK, Menon IS, Marimuthu P (2017) An exploration of use of social networking sites amongst users with psychological problems. Asian Journal of Psychiatry 18: 22-31.

10. Masthi NR, Pruthvi S, Phaneendra MS (2018) A comparative study on social media usage and health status among students studying in pre-university colleges of urban Bengaluru. Indian journal of community medicine: official publication of Indian.

11. Bhargava A, Rani M (2015) The influence of social media on Indian teenagers. International Journal of Science, Technology \& Management.

12. Raj M, Bhattacherjee S, Mukherjee A (2018) Usage of online social networking sites among school students of Siliguri, West Bengal, India. Indian J Psychol Med 40: 452457. [Crossref]

13. Bhardwaj A, Avasthi V, Groundar S (2017) Impact of Social Networking on Indian Youth-A Survey. International Journal of Electronics and Information Engineering 7: 41-51.

14. Saranya M (2016) An Empirical study on the usage pattern of Social Media among Youths with Reference to Bangalore City. Research Journal of Social Science \& Management 6: 8 .

15. Peluchette J, Karl K (2008) Social networking profiles: An examination of student attitudes regarding use and appropriateness of content. Cyberpsychol Behav 11: 95-97. [Crossref]

16. Ghaderi A, Motmaen M, Abdi I, Rasouli-Azad M (2017) Gender differences in substance use patterns and disorders among an Iranian patient sample receiving methadone maintenance treatment. Electron Physician 9: 5354-5362. [Crossref]

17. Malviya A, Dixit S (2014) A Study to Evaluate Internet Addiction Disorder among Students of a Medical College and Associated Hospital of Central India. National journal of Community Medicine 5: 93-95.

18. Gedam SR, Shivaji IA, Modi L, Ghosh S (2016) Comparison of internet addiction, pattern and psychopathology between medical and dental students. Asian J Psychiatr 22: 105-110. [Crossref]

19. Sharma MK, Rao GN, Benegal V, Thennarasu K, Thomas D (2017) Technology addiction survey: An emerging concern for raising awareness and promotion of healthy use of technology. Indian J Psychol Med 39: 495-499. [Crossref]

20. Kapoor KK, Tamilmani K, Rana NP, Patil P, Dwivedi YK (2018) Information System Frontiers 20: 531-558.

21. Kirik AM, Arslan A, Cetinkaya A, Mehmet GUL A (2015) Quantitative research on the research on the level of social media addiction among young people in Turkey. Int J SCS 3: $108-122$.

22. Dufour M, Brunelle N, Tremblay J, Leclerc D, Marie-Marthe C, et al. (2016) Gender difference in Internet Use and Internet Problems among Quebec High School students. Can J Psychiatry 61: 663-668. [Crossref]
23. Di Capua I (2012) A Literature of Research on Facebook Use. The Open Communication Journal 6: 37-34.

24. Sumter RS, Vandenbosch L (2018) Dating gone mobile: Demographic and personalitybased correlates of using smartphone-based dating applications among emerging adults.

25. Chan WSY, Leung AYM (2018) Use of Social Network Sites for Communication among Health Professionals: Systematic Review. J Med Interner Res 20: e 117. [Crossref]

26. Fardouly J, Willburger BK, Vartanian LR (2018) Instagram use and young women's body image concerns and self-objectification: Testing mediational pathways 20: 13801395.

27. Klinkhoff C (2017) The effects of Online Social Networking on Social Connectedness and Friendship Quality among Adolescents. PCOM Psychology Dissertations 416

28. Bhardwaj A, Goundar S, Avasthi V (2017) Impact of Social Networking on Indian Youth-A Survey. International Journal of electronics and Telecommunications 7: 41-51.

29. Madaiah M, Seshaiyengar CT, Suresh P, Munipapanna S, Sonnappa SD (2016) Study to assess the effects of social networking sites on medical college students. International Journal of Community Medicine and public Health.

30. Sharma MK, Chaturvedi SK, Mellor D (2017) Facebook storytelling: Implications for expression of coping behaviors. Journal of Mental Health and Human Behavior 22: 61-62.

31. Christakis DA, Moreno MA (2009) Trapped in the Net. Will internet addiction become a 21st century epidemic? Arch Pediatr Adolesc Med 163: 937-943. [Crossref]

32. Beard K (2002) Internet addiction. Current status and implications for employees. $J$ Employ Couns 39: 2-11.

33. Kelly Y, Zilanawala A, Booker C, Sacker A (2018) Social Media Use and dolescent Mental Health: Findings from the UK Millennium Cohort Study. EClinical Medicine 6: 59-68.

34. Gunuc S, Dogan A (2013) The relationships between Turkish adolescents Internet addiction, their perceived social support and family activities. Computers in Human Behavior 29: 2197-2207.

35. Ariani DW, Susilo YS (2018) Why do it Later? Goal Orientation, Self-efficacy, Test Anxiety on Procrastination.

36. Akhtar S, Khan A (2019) Internet usage and associated factors among college students in Saudi Arabia. International Journal of Community Medicine and Public Health 6 : 2331-2334

37. Jenaro C, Flores N, Gómez-Vela M, González-Gil F, Caballo C (2007) Problematic internet and cell-phone use: Psychological, behavioral, and health correlates. Addiction Research \& Theory 15: 309-320.

38. Gao H, Hu J, Wilson C, Li Z, Chen Y, et al. (2010) Detecting and characterizing socia spam campaigns. In: Proceedings of the 17th ACM Conference on Computer and Communications Security, CCS '10. ACM, New York, NY, USA: 681-683.

Copyright: (C2020 Baglari H. This is an open-access article distributed under the terms of the Creative Commons Attribution License, which permits unrestricted use, distribution, and reproduction in any medium, provided the original author and source are credited. 